\title{
Espiritualidade Ecológica O caminho do coração Partilha de uma experiência
}

\author{
Helena Teresinha Rech STS
}

Agradeço o convite para fazer parte da semana teológica e poder partilhar a experiência que venho realizando em assessorias, em nível de Brasil, sobre Eco-espiritualidade, em especial na orientação de "Retiros Ecológicos".

Minha proposta é refletir a "Espiritualidade Ecológica - como caminho do coração". Por isso, partilhar minha experiência é falar a partir do coração. Entendo que o caminho do coração é o caminho da simplicidade, da cotidianidade, do aprendizado - nos passos de Jesus como discípula.

A Espiritualidade é dom do Espírito. Ele cava em nosso interior a sede de Deus, suscita desejos profundos de vida plena para todos, nos provoca a viver com ética e sensibilidade, nos mergulha na fonte do amor, na Trindade, nos torna seres ecológicos.

A experiência espiritual é vida, é movimento, é processo, compromisso, mergulho, entrega, saída de si, conversão, êxodo.

A Espiritualidade cristã, a mística, a contemplação sempre foram minha paixão. Sempre me atraíram e fascinaram desde muito cedo, já na minha adolescência e juventude. A Vida Consagrada foi um caminho que me propiciou meios e me ajudou a fazer um itinerário espiritual pessoal e comunitário.

A missionariedade e a inserção em meios populares desde os meus 20 anos muito me ajudaram a crescer e vivenciar a Espiritualidade no cotidiano. No contato com os pobres, com as CEBs, com o povo simples, percebi que a Espiritualidade e a mística foram criando contornos diferentes daqueles que eu conhecia e vivenciava. Percebia Deus se revelando no cotidiano, nos desafios, no silêncio do coração. Na pobreza Ele se revelava como o Deus que desce e 
se encarna; na solidão, Ele procurava se deixar encontrar pelo seu povo; na dor e na fragilidade se fazia compaixão, ternura e amor; no desespero, escutava o clamor do povo; na negação da vida era entranhas maternas geradoras de vida nova... Contemplar e experienciar esta realidade do povo, me fez sentir, experienciar e trabalhar uma Espiritualidade Encarnada e Libertadora.

Prossegui trabalhando nas assessorias, na escuta e contemplação do pobre e do pulsar do coração de Deus Trino no meio deles. Conclui meu doutorado em Espiritualidade e me dediquei a escrever e trabalhar a "Espiritualidade Integradora" levando em conta o ser humano como um todo relacional. Durante nove anos criei e integrei uma Equipe interdisciplinar, onde trabalhávamos a dimensão espiritual, psicológica, corporal, afetiva, médica, a alimentação natural, de forma integradora. Assessorei muitos cursos e retiros nesta perspectiva. Destes encontros participou gente de vários Estados e cidades do Brasil. Um trabalho frutuoso e de qualidade que marcou muitas pessoas levando-as a assumir a vida pessoal, espiritual e profissional de forma integral, com qualidade e novas relações.

A Espiritualidade Integradora é dinâmica e foi aguçando meu lado de mulher "curiosa", observadora, criativa, em busca do novo. Comecei de forma intuitiva a integrar em meu trabalho a dimensão da ecologia. Como microcosmo em nós existem todos os elementos da natureza. Portanto somos parte do todo e o todo está em nós.

Percebei que a experiência espiritual integradora-ecológica fazia muito bem às pessoas. Que havia resgate de energia, integração pessoal e grupal, profundidade, harmonia, desaceleração da agitação dos tempos modernos, qualidade de vida e uma nova espiritualidade, mais profunda e comprometida com a vida e com a alteridade.

Fiz um curso de Pós-graduação Lato Sensu: "Espiritualidade, Ecologia e Educação: uma abordagem transdisciplinar", que veio confirmar e impulsionar-me no ministério teológico-espiritual.

A espiritualidade ecológica é um meio para uma consciência ecológica. Uma consciência que não é apenas saber intelectual, mas saber do coração, sabedoria que nasce de dentro. Conscientizar-se de que somos parte do planeta, do universo, uns dos outros e que todos os seres vivos formamos a grande comunidade de vida. A consciência ecológica nascida da Contemplação é o início de uma jornada muito longa. Assim como a árvore gigante nasce de uma semente minúscula, e experiência seminal da contemplação, gradativamente nos torna seres ecológicos. A linha divisória entre meu mundo interior e o mundo exterior começa a diminuir à medida que aprofundamos o nível de contemplação no qual nos contemplamos a nós mesmos enquanto seres viventes e parte de um todo maior. Em outras palavras, a duali- 
dade "contemplador e contemplado" desaparece na unidade de um fluxo integrador de consciência de "ser parte".

\begin{abstract}
"A capacidade de viver, em última análise, a totalidade da existência de forma ilimitada integral não está confinada a nenhuma cultura, raça ou religião em particular. Essa experiência de unidade inefável algumas vezes á chamada de Sabedoria Perene, porque aparece nos registros históricos das principais tradições do mundo: cristianismo, budismo, hinduísmo, taoísmo, judaísmo, islamismo, etc."
\end{abstract}

Pelo caminho da contemplação diária da Palavra de Deus, da natureza, da alteridade, dos acontecimentos, do universo, enfim, de nosso cotidiano com todas as suas nuances, tomamos consciência e iremos descobrir que aquilo que nós somos não é separado do Deus Trindade, do Cosmo, do universo: Deus está dentro de nós, a Trindade nos habita; a luz do sol, o brilho das estrelas, a beleza dos astros estão em nós; todos os elementos da natureza estão em nós. Somos parte!

A experiência de unidade, totalidade ou amor encontra-se no cerne das grandes tradições espirituais. Somo seres humanos e partilhamos percepções comuns.

Através da contemplação descobriremos que a Vida é um todo não fragmentado. Portanto, acredito que Espiritualidade é um caminho que nos leva a mudança interna e novas relações conosco, com as alteridades, com o cosmo, com o universo, com todas as formas de VIDA. A ecologia é relação, pertença, cuidado. E a experiência pessoal e de meu trabalho teológico espiritual tem demonstrado isso.

Roberto Crema $^{2}$ define assim a Espiritualidade sem se reportar a nenhuma religião:

"Espiritualidade é uma consciência não dual, uma consciência de uma participação da parte no todo que na essência é o amor e na prática é a solidariedade." ${ }^{3}$

Segundo Roberto Crema, uma pessoa que despertou para a Espiritualidade é uma pessoa que não se vê separada do outro, da comunidade e do universo.

\footnotetext{
${ }^{1}$ EIGIN Duene, Simplicidade Voluntária, Cultrix, 2007.

${ }^{2}$ Escritor e Vice-Reitor da Universidade Holística da Paz.

${ }^{3}$ Retirado de http://gaian.zip.net. Acesso em 21/10/10.
} 
Logo, se eu me sinto não-separada, colocaria fogo no seu corpo? - se me sinto não-separada do outro jogaria fogo em alguém dormindo num banco de praça, faria xixi no morador de rua que dorme debaixo de uma marquise, negaria acolher, escutar, alimentar alguém que me pede ajuda?

- se me sinto não-separada da natureza, iria empesteá-la e destruir os ecossistemas por uma neurose de progresso compulsivo? Iria contaminar as águas, o ar, acabar com os rios, com as espécies?

Existe o lado sombrio dessa religião do progresso a qualquer custo. Como também o investimento tecnológico, científico trouxe frutos notáveis sintetizados na tecnociência maravilhosa de que dispomos.

Há igualmente necessidade de um investimento significativo no mundo da subjetividade, da alma, da ética, da consciência, da essência.

Felizmente toda crise é oportunidade de crescer e assumir uma nova consciência! Uma antiga lição talvez esteja esquecida: "de que serve o mundo inteiro se você perdeu sua alma?" se você se perdeu? Se você esqueceu do SER que lhe faz ser?

Acredito que o ser humano já é e será a maior descoberta do Terceiro Milênio. Investir na alma, na Espiritualidade, na consciência é uma estratégia que poderá viabilizar a perpetuação com qualidade e dignidade da espécie humana e do nosso "planeta azul".

O prefixo "Eco" (grego: oikos ), significa casa, o lugar onde se vive. Ecologia significa a ciência das inter-relações da Casa.

Eco-Espiritualidade é o caminho interior de resignificação da Casa. Da Carta da Terra podemos extrair e aplicar à Eco-espiritualidade este texto: "reconhecer que todos os seres são interligados e cada forma de vida tem valor, independentemente do uso humano", Sim, reconhecer que somos seres dependentes uns dos outros como os fios de uma grande "teia de aranha". Se um fio se rompe toda a teia sofre o impacto. Na teia todos os fios são importantes e nenhum pode ficar sem o outro, estão interligados. A multiplicidade de fios forma uma única e linda engenharia da teia.

A Eco-Espiritualidade é um jeito de resignificar a Espiritualidade tendo em vista os desafios pelos quais passa a VIDA e a MÃE-TERRA. É um modo de viver de forma integrada e harmoniosa com a totalidade das relações da Casa, através do cuidado e do respeito com toda a "Comunidade de Vida", reconhecendo nossa Fonte originária de onde tudo provém, Deus Trindade, da qual buscamos aprender a vivência das relações.

\footnotetext{
${ }^{4}$ Carta da Terra, Princípios, p. 17, item a.

${ }^{5}$ Expressão da Carta da Terra.
} 
A Eco-espiritualidade tem como desafio:

1. Tirar o ser humano do centro, do antropocêntrismo. O humano é elo ético e não centro; é parte e não dono, é eco-relação e não único.

2. Valorizar o dom da cooperação e não a lei da competição. Cuidar dos mais fracos, integrar o que está desintegrado e o que está perdido;

3. Espiritualidade é o profundo do humano, é elo que une e reúne; buscar crescer a generosidade, acolher o diferente, abrir espaços para o novo e para a vivência da mística do cuidado;

4. Integrar todas as coisas. O ser humano é um microcosmo, parte do todo. Como se entende?

5. Ressacralizar as "casas": o planeta, a natureza, a casa, o corpo como morada da Trindade, o coração como morada da alma. Como me relaciono com meu habitat, nossa Casa comum?

\section{Experiência dos "Retiros Ecológicos"}

O Retiro ecológico que venho orientando há três anos tem como objetivo oportunizar uma experiência de Deus através da contemplação e da ecologia. A dinâmica do retiro é toda em contato com a natureza e feita de forma contempletiva: contemplar a Vida, a natureza, a vida pessoal, a missionariedade, as pessoas, com uma iluminação bíblica. Deixar que tudo passe dos olhos para o coração, do ver para o sentir, do experienciar cada coisa para o ser parte do todo, do tocar para o ser tocada.

O retiro ecológico é um grande convite à contemplação como caminho do coração e da sabedoria, que nos leva a admirar, saborear, encantar pelas maravilhas da criação, experienciar-se como parte e provar como o Senhor é bom. A contemplação é um caminho que nos abre internamente para o belo, o cuidado, a acolhida, o bem, o diálogo, as relações, o novo olhar, o sentido de pertença, reverência diante do mistério da vida, da alteridade, do Grande Outro, Deus Trindade. Tira tuas sandálias, pois a terra onde pisas é santa. Tira tuas sandálias pois o outro é corpo sagrado. Tira suas sandálias, pois a biodiversidade é sagrada, habitada, parte de sua vida e você da vida dela.

A contemplação é o espaço da integração com toda a criação e com o Criador, no Filho Jesus, o Primogênito de tudo. Na carta aos Colossesnses, Paulo escreve:

"Ele é a imagem do Deus invisivel, o promogênito de toda criação, pois é nele que foram criadas todas as coisas, no céu e na terra... pois Deus quis fazer habitar nele toda a plenitude e, por ele, reconciliar consigo todos os seres, tanto na terra como no céu" (1, 15-20). 
Todas as criaturas e o universo são sagrados, habitados pelo Verbo trinitário. Nele habita a plenitude da Vida e Ele habita, pela encarnação, a nosso mundo como Primogênito. O mundo é transpassado, penetrado pelo "Logos" criador, élo que une e reune todos os seres do céu e da terra. Nesta comunhão trinitária do Pai e do Filho, no Espírito vifificador, somos chamados/as à comunhão na pluralidade e na diferença. A criação tem seu espaço em Deus e Ele habita a Criação, seu santuário ecológico.

Dentro da contemplação emergem apelos e desejos profundos que levam a posturas e atitudes éticas, de indignação diante da injustiça, da desigualdade, da destruição da natureza, do desreipeito à vida humana, e todos os males que assolam a "Comunidade de Vida".

A contemplação nos faz pessoas sensíveis às injustiças, à depredação e destruição da natureza. A espiritualidade integradora ecológica nos abre à solidariedade com as pessoas e o planeta. Trana-nos pessoas de comunhão, construtoras da Paz e da justiça.

Contemplar é olhar com o coração aquilo os olhos não enxergam. É ver além daquilo que se vê. É penetrar a realidade com o olhar de Deus e sua ternura.

Contemplação é caminho do coração e sabedoria. Sabedoria é seguir tentando, com respeito, humildade, cuidado e paz. Onde há sabedoria nascida da contemplação, não a lixo nem exclusão, há seres em relação. Quando vivemos nossa essencia de seres relacionais, fazemo-nos ouvintes da Palavra que vem de todos os seres e das redes de comunicação que se estabelecem com o todo e mais nos tornamos seres de comunhão e integração, seres ecológicos.

No roteiro do "Retiro Ecológico", além dos textos bíblicos, da reflexão e experiências com a natureza, utilizamos filmes relacionados com o tema, poemas, relaxamentos, danças sagradas, celebrações, simbolos e um roteiro de oração e textos bíblicos para cada dia. Sei não ser oportuno anexar aqui esses roteiros, pois são apenas um meio. A experiência do Retiro Ecológico não tem como escrever, pois é vida e experiência de vida é indizivel, se experimenta.

Mas, posso avaliar como positiva essa experiência e sinto que seu objetivo tem sido atingido: através da contemplação criar uma consciência ecológica, uma mística do cuidado do Planeta, dos ecosistemas, da natureza e de toda a Vida, sentindo-se parte, relacionando-se com respeito e sensibilidade, abertura e amor.

Deus Trindade Fonte da vida e das relações nos possibilite sermos pessoas ecológicas comprometidas com a vida. 
Quero concluir esta simples partilha com um pensamento de L. Boff

"A missão do ser humano reside em poder captar os mil ecos que vêm dessa grande Voz que reboa de ponta a ponta do universo e que vibra em cada ser. Cabe-nos unir nossa voz a esse eco universal; somos chamados a ser sinfônicos e a venerar o Maestro dessa imensa orquestra cósmica... Deus, vivificador e atrator de todas as coisas para seu seio paternal e maternal”.

Com ternura partilho um poema nascido num retiro ecológico:

\section{A BÊNÇÃO DA VIDA}

Há milhões e milhões de anos, quando tudo já havia sido criado, a Divina Sabedoria contemplou e viu que tudo era tão belo, iluminado e uma infinidade de relações colocava o cosmos em movimento...

Como numa grande teia, tudo estava entreligado, transligado, interligado. As singularidades eram partes do todo e tudo estava nas partes.

Havia uma dança de vida que movia o universo e ele bailava ao ritmo de vários instrumentos e sons, cores e melodias tornando-o harmonioso e plural, repleto de tons e sons, tornando-o simplesmente encantador!

Água cristalina, natureza exuberante, planetas e cometas, sol e lua, terra e rochas, planícies e montanhas, fogo e calor, gelos e neves, flores e espinhos, árvores e arbustos, frutos, peixes e animais, vento e chuva, rios e mares...

uma bênção para a vida e a existência de tudo o que vive e respira!

Quando quase tudo já existia, a Mãe Divina plantou um jardim no Édem, no Oriente e ali engravidou.

Gerou e pariu das entranhas da terra o ser humano.

E fez questão de formá-lo de uma pitada de cada elemento

do planeta terra e do universo.

Colocou muito cuidado para que nada faltasse

para que a mulher e o homem se sentissem parte do todo.

Nem menos, nem mais

${ }^{6}$ L. Boff, A voz do Arco Íris, p. 133. 
Nem maior, nem menor

Nem dono, nem escravo

mas parte integrante.

A Mãe Divina colocou a última pitada que fazia a diferença:

a capacidade de AMAR, de CUIDAR e se tornar benção de Deus.

A Mãe Divina viu que tudo era tão belo

e deu a grande benção da VIDA

para que todo o criado se tornasse

vida abençoada e benção de VIDA.

\section{Referências Bibliográficas}

L. Boff, “A voz do Arco Íris”, Editora Sextante, 2004.

SOTER (0rg), "Sustentabilidade da Vida e Espiritualidade", Paulinas, 2008.

ELGIN, Duane, "Simplicidade Voluntária", Cultrix, 2007.

GRÜN, Anselm, "O ser fragmentado, da cisão à integração", Idéias \&Letras, 2004.

MOSER, Antônio, "O problema ecológico", Vozes, 1992.

SKA, Jean Louis, "O Deus - Oleiro, Dançarino e Jardineiro", Loyola, 2001.

\section{Resumo}

A espiritualidade ecológica é um meio para se adquirir uma consciência ecológica. Uma consciência que não é apenas saber intelectual, mas saber do coração, sabedoria que nasce de dentro. Conscientizar-se de que somos parte do planeta, do universo, uns dos outros e que, com todos os seres vivos, formamos a grande comunidade de vida. A consciência ecológica, nascida da Contemplação, é o início de uma jornada muito longa. Assim como a árvore gigante nasce de uma semente minúscula, a experiência seminal da contemplação, nos torna, gradativamente, seres ecológicos. A linha divisória entre o meu mundo interior e o mundo exterior começa a diminuir na medida em que aprofundamos o nível de contemplação, no qual nos contemplamos a nós mesmos enquanto seres viventes e parte de um todo maior. Em outras palavras, a dualidade entre contemplador e contemplado desaparece na unidade de um fluxo integrador de consciência de ser parte de um todo. Quanto mais formos humanos, mais seremos espirituais e ecológicos.

Palavras-chave: Eco-espiritualidade, Consciência Ecológica, Contemplação, Ser Parte. 


\begin{abstract}
The ecological spirituality is a means to acquire an ecological conscience. A conscience that is not just intellectual knowledge, but knowledge of the heart, wisdom that comes from within. Aware that we are part of the planet, the universe, of each other and with all living beings, we form the greater community of life. The ecological awareness, born of Contemplation, is the beginning of a very long journey. Just as a giant tree rises from a tiny seed, from the seminal experience of contemplation, we become gradually ecological beings. The dividing line between my inner world and outer world begins to diminish as we deepen the level of contemplation in which we contemplate ourselves as living beings and part of a larger whole. In other words, the duality "and contemplative" disappears in the unit of a flow integrating consciousness of being "part" of a whole. The more we are human, the more $\hat{A}$ we will be spiritual and ecological.
\end{abstract}

Keywords: Eco-spirituality, Ecological Awareness, Contemplation, Be Part of.

Helena Teresinha Rech

Religiosa da Congregação das Servas da Santíssima Trindade Membro do Conselho Editorial da Revista Convergência

Assessora de cursos, retiros e palestras Doutora em Espiritualidade E-mail: helenarech@ig.com.br

Comunicação Recebida em 07/01/2011

Comunicação Aprovada em 05/04/2011 